\section{Structural and functional alterations of the cell nucleus in skeletal muscle wasting: the evidence in situ}

\author{
M. Malatesta,' G. Meola ${ }^{2}$ \\ 'Dipartimento di Scienze Neurologiche, \\ Neuropsicologiche, Morfologiche e \\ Motorie, Sezione di Anatomia e Istologia, \\ Università di Verona, Italy; ${ }^{2}$ Dipartimento \\ di Neurologia, IRCCS Policlinico San \\ Donato, Università degli Studi di Milano, \\ Italy
}

\begin{abstract}
The histochemical and ultrastructural analysis of the nuclear components involved in RNA transcription and splicing can reveal the occurrence of cellular dysfunctions eventually related to the onset of a pathological phenotype. In recent years, nuclear histochemistry at light and electron microscopy has increasingly been used to investigate the basic mechanisms of skeletal muscle diseases; the in situ study of nuclei of myofibres and satellite cells proved to be crucial for understanding the pathogenesis of skeletal muscle wasting in sarcopenia, myotonic dystrophy and laminopathies.
\end{abstract}

In recent years, histochemistry has become a popular approach to investigate the structural organization and function of skeletal muscle cells, ${ }^{1-8}$ being widely used as a diagnostic tool in neuromuscular disorders. ${ }^{9,10}$ In particular, the cytochemical analysis of the cell nucleus has been applied more and more frequently for investigating the basic mechanisms of skeletal muscle diseases.

In the cell nucleus, genes are transcribed and the primary transcripts undergo molecular processing which generates mature RNAs to be exported into the cytoplasm. The events leading to the formation of mature RNAs are chronologically and spatially ordered, and they mostly occur on distinct ribonucleoprotein (RNP)-containing structures. ${ }^{11,12}$ These nuclear components have specific locations, and this is a necessary prerequisite for the correct processing of nuclear RNAs to occur, so that whenever transcription and/or splicing are altered, the organization, composition, and intranuclear location of RNP-containing structures are also affected. ${ }^{13-16}$ As a consequence, the in situ analysis of the nuclear organization and molecular composition in muscle cells not only provides information about the DNA/RNA pathways which govern myofibre metabolism, but also may reveal the occurrence of dysfunc- tions related to the pathological phenotype of diseased skeletal muscle.

Recently, ultrastructural immunocytochemical investigation of cell nuclear components has been applied to study sarcopenia, ${ }^{17,18}$ i.e. the age-related condition characterized by the decline of muscle mass, strength and quality, which is responsible for frailty, disability and premature death in elderly. ${ }^{19}$ The cellular mechanisms involved in the onset of sarcopenia are probably manifold, and they still remain to be completely elucidated. ${ }^{20,21}$ One of the possible causes is the remarkable decline in the efficiency of muscle regeneration, which has been associated with a decrease in the number of satellite cells and/or with the alteration of their proliferation and differentiation potential. ${ }^{22,23}$ Consistent with this hypothesis, through the in situ analysis of the nuclear RNP-containing structures involved in the different steps of mRNA formation, it has recently been demonstrated that satellite cells of old muscles exhibit a significantly reduced activity of pre-mRNA splicing and cleavage, which hampers their responsiveness to muscle damage. ${ }^{18}$ In addition, the cytochemical approach allowed to demonstrate that the entire production chain of mRNA, from its synthesis to the export into the cytoplasm, is impaired in the myonuclei of old muscles: ${ }^{17}$ this would likely contribute to the reduced responsiveness of muscle fibres to anabolic stimuli, as it typically occurs in elderly. It may be inferred that many of the structural and functional alterations occurring in old muscles could be the phenotypic expression of a failure in nuclear functions. Accordingly, when the sarcopenic process is prevented by physical activity, ${ }^{24,25}$ the cell nuclei of senescent skeletal muscles show the RNP pattern typical of the adult age (personal unpublished results). It is worth noting that in hibernating mammals the muscle mass is maintained even after long periods of inactivity (which may last for months, in some species): in the skeletal muscles of hibernating mammals the nucleus displays "active" characteristics, ${ }^{26}$ thus suggesting that preservation of the myofibre/muscle structure implies the maintenance of a correct nuclear functionality.

Defects in the RNA maturation pathways have also been related to diseases leading to muscle dystrophy: in both the myotonic dystrophy type 1 (DM1) and type 2 (DM2) the expansion of two distinct nucleotidic sequences ((CTG)n in the 3' untranslated region of the DMPK gene on chromosome $19 q 13$ in DM1 ${ }^{27-29}$ and (CCTG)n in the first intron of the ZNF9 gene on chromosome $3 q 21$ in DM2 $2^{30,31}$ ) causes pathologies characterized by a variety of multisystemic features including myotonia (muscle hyperexcitability), muscular dystrophy, dilated cardiomyopathy, cardiac conduction defects,
Correspondence: Dr. Manuela Malatesta, Dipartimento di Scienze Neurologiche, Neuropsicologiche, Morfologiche e Motorie, Sezione di Anatomia e Istologia, Università degli Studi di Verona, strada Le Grazie 8, 37134 Verona, Italy. E-mail: manuela.malatesta@univr.it

Key words: cell nucleus, histochemistry, skeletal muscle, sarcopenia, myotonic dystrophy, laminopathies.

Received for publication: 8 September 2010. Accepted for publication: 9 September 2010.

This work is licensed under a Creative Commons Attribution 3.0 License (by-nc 3.0).

(C) Copyright M. Malatesta and G. Meola, 2010 Licensee PAGEPress, Italy

European Journal of Histochemistry 2010; 54:e44 doi:10.4081/ejh.2010.e44

cataracts, insulin-resistance, and disease-specific serological abnormalities such as hyperglycemia and gamma-glutamyltransferase elevations, hypotestosteronism, and decreased levels of $\operatorname{IgG}$ and IgM immunoglobulins. Combining biomolecular and cytochemical techniques, it has been demonstrated that the basic mechanisms of both DMs reside in the nuclear sequestration of the expanded RNAs: CUG- and CCUG-containing transcripts accumulate in intranuclear foci in DM1 and DM2 cells respectively, and alter the regulation and intranuclear localization of the RNA-binding proteins CUGBP1 and MBLN, which are necessary for the physiological processing of premRNA. ${ }^{31-37}$ A recent study based on immunocytochemical analyses at light and electron microscopy ${ }^{38}$ has demonstrated that MBNL1containing foci in DM2 cells also sequester snRNPs and hnRNPs, splicing factors involved in the early phases of transcript processing; ${ }^{11}$ this strengthens the hypothesis that the multifactorial phenotype of dystrophic patients could be due to a general alteration of the premRNA post-transcriptional pathway.

Laminopathies represent a family of multisystemic disorders resulting from mutations in the LMNA gene on chromosome 1q21, encoding nuclear lamins A and C. They include several distinct disease phenotypes, many of which characterised by skeletal muscle dystrophy ${ }^{39}$ Also in this case, the combination of biomolecular and cytochemical studies revealed that the basic mechanisms of the pathological features reside in the nucleus, where prelamin $\mathrm{A}$ is accumulated, heterochromatin undergoes a severe disorganisation and many heterochromatin-associated proteins show altered properties. ${ }^{39-42}$ This defective heterochromatin remodelling affects gene expression thus causing a cascade of epigenetic 
events altering several systems.

The analysis in situ of the cell nucleus may therefore represent a decisive approach for understanding the basic mechanisms leading to fibre muscle loss/disorganization, which is crucial for the development of effective interventions to fight physical disability. This type of investigation requires that sufficient amounts of bioptic material are adequately removed and processed in order to obtain reliable results; however, this is scarcely compatible with the surgical needs and, for a long time, this restriction has limited the application of in situ techniques to investigate muscle physiopathology. The recent demonstration that routinely frozen biopsies of human skeletal muscle can be successfully processed for morphological and immunocytochemical studies at transmission electron microscopy ${ }^{43}$ opens promising perspectives for multiple exploitation of the bioptic muscle samples stored in tissue banks, especially for the study of rare muscle diseases.

\section{References}

1. Pompili E, De Luca A, Nori SL, Maras B, De Renzis G, Ortolani F, et al. Biochemical and immunohistochemical evidence for a non-muscle myosin at the neuromuscular junction in bovine skeletal muscle. $\mathrm{J}$ Histochem Cytochem 2003;51:471-8.

2. Vogel H, Zamecnik J. Diagnostic immunohistology of muscle diseases. J Neuropathol Exp Neurol 2005;64:181-93.

3. Anastasi G, Cutroneo G, Santoro G, Arco A, Rizzo G, Trommino C, et al. Integrins, muscle agrin and sarcoglycans during muscular inactivity conditions: an immunohistochemical study. Eur $\mathbf{J}$ Histochem 2006;50:327-36.

4. Bellafiore M, Cappello F, Palumbo D, Macaluso F, Bianco A, Palma A, et al. Increased expression of titin in mouse gastrocnemius muscle in response to an endurance-training program. Eur J Histochem 2007;51:119-24.

5. Lehnert M, Laurer H, Maier B, Frank J, Marzi I, Steudel WI, et al. The histochemical profile of the rat extensor digitorum longus muscle differentiates after birth and dedifferentiates in senescence. Eur $\mathrm{J}$ Histochem 2007;51:111-8.

6. Smerdu V, Soukup T. Demonstration of myosin heavy chain isoforms in rat and humans: the specificity of seven available monoclonal antibodies used in immunohistochemical and immunoblotting methods. Eur J Histochem 2008;52:179-90.

7. Karen P, Stevanec M, Smerdu V, Cvetko E, Kubínová L, Erzen I. Software for muscle fibre type classification and analysis. Eur J Histochem 2009;53:87-95.

8. Meunier B, Picard B, Astruc T, Labas R. Development of image analysis tool for the classification of muscle fibre type using immunohistochemical staining. Histochem Cell Biol 2010;134:307-17.

9. Meola G. Advanced microscopic and histochemical techniques: diagnostic tools in the molecular era of myology. Eur $\mathbf{J}$ Histochem 2005;49:93-6.

10. Tews DS, Goebel HH. Diagnostic immunohistochemistry in neuromuscular disorders. Histopathology 2005;46:1-23.

11. Fakan S. Ultrastructural cytochemical analyses of nuclear functional architecture. Eur J Histochem 2004;48:5-14.

12. Cremer T, Cremer C. Rise, fall and resurrection of chromosome territories: a historical perspective Part II. Fall and resurrection of chromosome territories during the 1950s to 1980s. Part III. Chromosome territories and the functional nuclear architecture: experiments and models from the 1990s to the present. Eur J Histochem 2006; 50:223-72.

13. Biggiogera M, Bottone MG, Scovassi AI, Soldani C, Vecchio L, Pellicciari C. Rearrangement of nuclear ribonucleoprotein (RNP)-containing structures during apoptosis and transcriptional arrest. Biol Cell 2004;96:603-15.

14. Biggiogera M, Cisterna B., Spedito A., Vecchio L., Malatesta M. Perichromatin fibrils as early markers of transcriptional alterations. Differentiation 2008;76:57-65.

15. Malatesta M, Biggiogera M, Baldelli B, Barabino SML, Martin TE, Zancanaro C. Hibernation as a far-reaching program for the modulation of RNA transcription. Microsc Res Tech 2008;71:564-72.

16. Malatesta M, Biggiogera M, Cisterna B, Balietti M, Bertoni-Freddari C, Fattoretti P. Perichromatin fibrils accumulation in hepatocyte nuclei reveals alterations of pre-mRNA processing during ageing. DNA Cell Biol 2010;29:49-57.

17. Malatesta M, Perdoni F, Muller S, Zancanaro C, Pellicciari C. Nuclei of aged myofibres undergo structural and functional changes suggesting impairment in RNA processing. Eur J Histochem 2009;53: 97-106.

18. Malatesta M, Perdoni F, Muller S, Pellicciari C, Zancanaro C. Pre-mRNA processing is partially impaired in satellite cell nuclei from aged muscles. J Biomed Biotechnol 2010;2010:410405.

19. Lang T, Streeper T, Cawthon P, Baldwin K, Taaffe DR, Harris TB. Sarcopenia: etiology, clinical consequences, intervention, and assessment. Osteoporos Int 2010;21:543-59. 20. Ryall JG, Schertzer J, Lynch GS. Cellular and molecular mechanisms underlying age-related skeletal muscle wasting and weakness. Biogerontology 2008;9:213-28.

21. Thompson LD. Age-related muscle dysfunction. Exp Gerontol 2009;44:106-11.

22. Musarò A, Giacinti C, Pelosi L, Dobrowolny G, Barberi L, Nardis C, et al. Stem cellmediated muscle regeneration and repair in aging and neuromuscular diseases. Eur J Histochem 2007;51 Suppl 1:35-44.

23. Verdijk LB, Koopman R, Schaart G, Meijer K, Savelberg HH, van Loon LJ. Satellite cell content is specifically reduced in type II skeletal muscle fibers in the elderly. Am J Physiol Endocrinol Metab 2007;292:E151-7.

24. Marcell TJ. Sarcopenia: causes, consequences, and preventions. J Gerontol A Biol Sci Med Sci 2003;58:M911-6.

25. Zancanaro C, Mariotti R, Perdoni F, Nicolato E, Malatesta M. Physical training is associated with changes in NMR and morphometrical parameters of the skeletal muscle in senescent mice. Eur J Histochem 2007;51:305-10.

26. Malatesta M, Perdoni F, Battistelli S, Muller $\mathrm{S}$, Zancanaro C. The cell nuclei of skeletal muscle cells are transcriptionally active in hibernating edible dormice. BMC Cell Biol 2009;10:19.

27. Brook JD, McCurrach ME, Harley HG, Buckler AJ, Church D, Aburatani H, et al. Molecular basis of myotonic dystrophy: expansion of a trinucleotide (CTG) repeat at the 3' end of a transcript encoding a protein kinase family member. Cell 1992;69:385-7.

28. Fu YH, Pizzuti A, Fenwick Jr RG, King J, Rajnarayan S, Dunne PW, et al. An unstable triplet repeat in a gene related to myotonic muscular dystrophy. Science 1992;255:1256-8.

29. Mahadevan M, Tsilfidis C, Sabourin L, Shutler G, Amemiya C, Jansen G, et al. Myotonic dystrophy mutation: an unstable CTG repeat in the 3' untranslated region of the gene. Science 1992;255:1253-5.

30. Ranum LP, Rasmussen PF, Benzow KA, Koob MD, Day JW. Genetic mapping of a second myotonic dystrophy locus. Nat Genet 1998;19:196-8.

31. Liquori CL, Ricker K, Moseley ML, Jacobsen JF, Kress W, Naylor SL, et al. Myotonic dystrophy type 2 caused by a CCTG expansion in intron 1 of ZNF9. Science 2001; 293:864-7.

32. Miller JW, Urbinati CR, Teng-Umnuay P, Stenberg MG, Byrne BJ, Thornton CA, et al. Recruitment of human muscleblind proteins to (CUG)(n) expansions associated with myotonic dystrophy. EMBO J 2000;19:4439-48.

33. Ladd AN, Charlet N, Cooper TA. The CELF family of RNA binding proteins is implicat- 
ed in cellspecific and developmentally regulated alternative splicing. Mol Cell Biol 2001;21:1285-96.

34. Fardaei M, Rogers MT, Thorpe HM, Larkin K, Hamshere MG, Harper PS, et al. Three proteins, MBNL, MBLL and MBXL, co-localize in vivo with nuclear foci of expandedrepeat transcripts in DM1 and DM2 cells. Hum Mol Genet 2002;11:805-14.

35. Cardani R, Mancinelli E, Sansone V, Rotondo G, Meola G. Biomolecular identification of (CCTG)n mutation in myotonic dystrophy type 2 (DM2) by FISH on muscle biopsy. Eur J Histochem 2004;48:437-42.

36. Cardani R, Mancinelli E, Rotondo G, Sansone V, Meola G. Muscleblind-like protein 1 nuclear sequestration is a molecular pathology marker of DM1 and DM2. Eur J Histochem 2006;50:177-82.

37. Cardani R, Mancinelli E, Giagnacovo M, Sansone V, Meola G. Ribonuclear inclu- sions as biomarker of myotonic dystrophy type 2, even in improperly frozen or defrozen skeletal muscle biopsies. Eur J Histochem 2009;53:107-11.

38. Perdoni F, Malatesta M, Cardani R, Giagnacovo M, Mancinelli E, Meola G, et al. RNA/MBNL1-containing foci in myoblast nuclei from patients affected by myotonic dystrophy type 2: an immunocytochemical study. Eur J Histochem 2009;53:151-8.

39. Maraldi NM, Lattanzi G, Capanni C, Columbaro M, Merlini L, Mattioli E, et al. Nuclear envelope proteins and chromatin arrangement: a pathogenic mechanism for laminopathies. Eur J Histochem 2006;50: 1-8.

40. Squarzoni S, Sabatelli P, Capanni C, Lattanzi G, Rutigliano C, Columbaro M, et al. Emerin increase in regenerating muscle fibers. Eur J Histochem 2005;49:355-
62.

41. Maraldi NM, Mazzotti G, Rana R, Antonucci A, Di Primio R, Guidotti L. The nuclear envelope, human genetic diseases and ageing. Eur J Histochem 2007;51 Suppl 1:117-24.

42. Dominici S, Fiori V, Magnani M, Schena E, Capanni C, Camozzi D, et al. Different prelamin A forms accumulate in human fibroblasts: a study in experimental models and progeria. Eur J Histochem 2009;53: 43-52.

43. Giagnacovo M., Cardani R., Meola G., Pellicciari C., Malatesta M. Routinely frozen biopsies of human skeletal muscle are suitable for morphological and immunocytochemical analyses at transmission electron microscopy. Eur J Histochem 2010;54:137-42. 